\title{
A NEW THERMAL PROCESS FOR THE RECOVERY OF METALS FROM ZINC-CARBON AND ALKALINE SPENT BATTERIES
}

\author{
${ }^{1}$ Girolamo Belardi, ${ }^{2}$ Roberto Lavecchia, ${ }^{2}$ Franco Medici, \\ ${ }^{2}$ Luigi Piga and ${ }^{2}$ Antonio Zuorro \\ ${ }^{1}$ Institute for Environmental Engineering and Geosciences, CNR, Monterotondo, Rome, Italy
${ }^{2}$ Department of Chemical Engineering, Materials and Environment, Sapienza University, Rome, Italy
}

Received 2014-04-01; Revised 2014-04-12; Accepted 2014-07-26

\begin{abstract}
The aim of this study is the thermal recovery of manganese and zinc from a mixture of zinc-carbon and alkaline spent batteries containing $40.9 \%$ of $\mathrm{Mn}$ and $30.1 \%$ of $\mathrm{Zn}$ after a preliminary physical treatment. Separation of the metals is carried out on the basis of their different phase change temperatures, the boiling point of zinc being $906^{\circ} \mathrm{C}$ and $1564^{\circ} \mathrm{C}$ that of $\mathrm{Mn}_{3} \mathrm{O}_{4}$, the main Mn-bearing phase in the mixture. After wet comminution and sieving to remove the anodic collectors and most of the chlorides contained in the mixture, chemical and X-Ray Powder Diffraction (XRPD) analyses were performed. The mixture was heated in $\mathrm{CO}_{2}$ atmosphere and the temperature raised, thus permitting the zinc oxide to be reduced to metallic zinc by the carbon present in the original mixture. Other tests were carried out by addition to the mixture of activated charcoal $(95 \% \mathrm{C})$ or of the automotive shredder residue (fluff) containing $45 \%$ C.A zinc product was obtained suitable, after refining, for the production of new batteries. The treatment residue consisted of manganese and iron oxides that could be used to produce manganese-iron alloys. From these results, an integrated process for the recovery of the two metals was proposed.
\end{abstract}

Keywords: Spent Batteries, Recycling, Manganese, Zinc, Metal Recovery

\section{INTRODUCTION}

Manganese and zinc are important metals in many fields. The increase in zinc demand is due to its increased consumption in Europe and to a consolidated growth of emerging economies (USGS, 2014) while, as far as manganese and iron are concerned, most of their consumption is related to steel production.

Alkaline and zinc-carbon spent batteries contain significant amounts of manganese and zinc (Belardi et al., 2011) and their recovery as secondary raw materials (De Michelis et al., 2007) could represent an economic benefit for the battery producers and reduce their environmental impact, as there would be smaller volumes to be disposed of, with an increase in the life of the landfill (Karnchanawong and Limpiteeprakan, 2009).
Iron is contained in the end caps, in the alkaline battery steel cans and, in some cases, in the steel outer jackets of the zinc-carbon batteries, while copper and zinc are present in the alkaline battery brass negative current collectors. These components could be easily removed and recycled from spent batteries, while an additional separation process is required for the recovery of manganese and zinc, since most of these metals are found in the paste inside the battery.

At present, hydrometallurgical and pyrometallurgical processes are used for the recovery of valuable metals from spent batteries (Bernardes et al., 2004; Almeida et al., 2009). Both methodologies are generally preceded by physical methods of separation to improve the efficiency of the successive recovery steps.

Hydrometallurgical processes are based on the dissolution of metals in acidic or basic media followed Corresponding Author: Franco Medici, Department of Chemical Engineering, Materials and Environment, Sapienza University, Rome, Italy 
by their selective recovery using solvent extraction or electrochemical methods (Sayilgan et al., 2009). Pyrometallurgical processes are the most widely used in industry and are based on the volatilization and condensation of zinc, with a consequent concentration of manganese in the residue (Belardi et al., 2012).

Generally, pyrometallurgical processes are considered more expensive than hydrometallurgical processes owing to the greater energy consumption. Nevertheless, most of the pyrometallurgical processes are large-scale operations and some of them can accept wastes like the paste of the batteries as a part of the common primary raw material feed without appreciable drawbacks in emissions and in the quality of their products. So, the metals of the spent batteries can be recovered and the process can also profit of the energy produced by the combustion of graphite and plastics contained in the battery waste. Hydrometallurgical plants are generally small-scale operations and have costs higher than those of pyrometallurgical plants. Nevertheless, they allow the production of high-purity electrolytic refined zinc (99.995\%) according to EN 1179 , suitable for battery production as reported in Table 1. At present, there is no specification for zinc metal for primary zinc batteries. In practice, zinc cans, for zinc-carbon batteries or powder, for alkaline batteries, are made from a new zinc quality and extensively tested by battery manufacturers. The major issue is corrosion and battery leakage caused by unwanted impurities such as $\mathrm{Fe}$ that is required to have a concentration below $3 \mathrm{mg} / \mathrm{kg}$ max and not $20 \mathrm{mg} / \mathrm{kg}$ as in the SHG. The zinc or zinc oxide produced by the pyrometallurgical route could be added to the feed of the final electrolytic step of a hydrometallurgical plant to reach the purity requested.

This study is part of a broader research project concerning the recovery of valuable metals from wastes containing hazardous materials in order to reduce their environmental impact the consumption of primary raw materials. In particular, we propose a new integrated process for the treatment of zinc-carbon and alkaline spent batteries operating at temperatures lower than those used in current processes (BATREC, RECUPY and REVABAT). The process consists of a preliminary physical separation and subsequent thermal treatment for the recovery of zinc and manganese. Zinc oxide can be reduced to metallic zinc using the carbon contained in the original mixture, if present in sufficient quantity (Belardi et al., 2014), or that derived from a different source. In this study, car fluff, also known as ASR (Automotive Shredder Residue), that is, the residue resulting from the dismantling of automotive vehicles (Vermeulen et al., 2011) is considered. Fluff is a highly heterogeneous material composed mainly of plastic, rubber/elastomer, metals, glass, textiles and other rubbles (Alunno Rossetti et al., 2006; Ruffino et al., 2014).
Table 1. Special High Grade (SHG) zinc for primary zinc batteries, according to EN 1179

\begin{tabular}{lll}
\hline Species & Value & Unit \\
\hline Zinc & $99.995 \mathrm{~min}$ & $\mathrm{wt} \%$ \\
Lead & $30 \mathrm{max}$ & $\mathrm{mg} / \mathrm{kg}$ \\
Iron & $20 \mathrm{max}$ & $\mathrm{mg} / \mathrm{kg}$ \\
Cadmium & $30 \mathrm{max}$ & $\mathrm{mg} / \mathrm{kg}$ \\
Copper & $10 \mathrm{max}$ & $\mathrm{mg} / \mathrm{kg}$ \\
Tin & $10 \mathrm{max}$ & $\mathrm{mg} / \mathrm{kg}$ \\
Aluminum & $10 \mathrm{max}$ & $\mathrm{mg} / \mathrm{kg}$ \\
Total $(\mathrm{Pb}+\mathrm{Fe}+\mathrm{Cd}+\mathrm{Cu}+\mathrm{Sn}+\mathrm{Al})$ & $50 \mathrm{max}$ & $\mathrm{mg} / \mathrm{kg}$ \\
\hline
\end{tabular}

\section{MATERIALS AND METHODS}

The original mix of zinc-carbon and alkaline batteries was shredded with a cutting mill and the fraction above 3 $\mathrm{mm}$ was milled and fed to a low-intensity magnetic separator to remove most of the iron. The non-magnetic fraction was sieved at $3 \mathrm{~mm}$ with removal of the largest particles of plastic and paper in the coarse fraction. The $<3$ $\mathrm{mm}$ fractions from sieving and from shredding were treated on a shaking table to remove the negative current collectors of the alkaline batteries. The last wet treatment also reduced the amount of chlorides from 1.24 to $0.1 \%$, then mitigating the aggressiveness of the material during the successive tests at high temperature. The battery paste obtained in the last step after drying was the feed to the thermal process.

Thermal desorption tests were carried out on the paste of alkaline and zinc-carbon spent batteries in pure $\mathrm{CO}_{2}$ at different temperatures and 30-min residence time. Activated charcoal $(95 \% \mathrm{C})$ or fluff $(45 \% \mathrm{C})$, were added to the paste of batteries. Their amounts were calculated so that the quantity of carbon exceeded by $30 \%$ the stoichiometric ratio of the reaction $\mathrm{ZnO}+\mathrm{C} \rightarrow \mathrm{Zn} \uparrow+\mathrm{CO}$ (i.e., $7.5 \mathrm{~g}$ of charcoal or $15.0 \mathrm{~g}$ fluff were added to $100 \mathrm{~g}$ paste, respectively). Moreover, the amount of carbon present in the paste of batteries (6-7\%), was not considered because carbon is contained only in zinc-carbon batteries rather than in the alkaline batteries and the former will go out of production within next years. As a consequence, addition of carbon will be needed for performing the reduction of the zinc oxide.

Glass and inert materials were removed from the fluff by the recycling company. Owing to the softness of the fluff, an ultra centrifugal mill was used for a rapid comminution of the material below $1 \mathrm{~mm}$ after removal, by preliminary sieving, of the fraction above $1 \mathrm{~cm}$. The fluff consisted of both thermosetting and thermoplastic components. While the former was easily grindable, the latter melted and underwent sintering during milling. This last fraction was milled with an agate ring mill together with the fraction above $1 \mathrm{~cm}$ so as to bring all the material below $1 \mathrm{~cm}$. 
Thermal treatments were carried out in a lab-plant consisting of a horizontal furnace with a uniform and central heated zone of $8 \mathrm{~cm}$ and a total heated zone of $25 \mathrm{~cm}$. A $50-\mathrm{cm}$ high, $4-\mathrm{cm}$ diameter quartz reactor was inserted very slowly in the furnace that had been brought before to the temperature fixed for the test. Finally, a sample of 8-9 $\mathrm{g}$ was placed in a porcelain boat that was then slowly introduced in the centre of the reactor. The $\mathrm{CO}_{2}$ stream was passed through the quartz tube at a rate of $0.9 \mathrm{~L} / \mathrm{min}$, both to permit the conversion of $\mathrm{CO}_{2}$ into $\mathrm{CO}$, according to Boudouard equilibrium and to help removing any vaporized material from the reactor. The outgoing stream was bubbled through two wash-bottles put one after the other and containing 100 and $50 \mathrm{~mL}$ of a $1 \mathrm{M} \mathrm{HNO}_{3}$ solution, respectively, to trap the zinc driven off from the sample that is both the metal reduced from $\mathrm{ZnO}$ and the metal existing as zinc in the paste of batteries. The zinc was present as zinc nitrate in the nitric solution, irrespectively of the form it was in the paste of batteries. The gas was released to the atmosphere after being passed through an activated carbon trap. After the scheduled residence time, counted from the moment the boat was introduced into the quartz tube, the furnace was switched off and the porcelain boat, containing the residue, was extracted and left to cool at a side of the quartz tube while still maintaining the stream of gas. The boat was left $10 \mathrm{~min}$ in a dessicator and then the residue was weighed, homogenized and sent for chemical analysis by atomic absorption spectrometry for the determination of $\mathrm{Fe}, \mathrm{Mn}$ and $\mathrm{Zn}$ and for X-ray diffraction to identify the main solid phases (Marruzzo et al., 2001).

The liquid of the two washing bottles was poured in a $250 \mathrm{~mL}$ volumetric flask and the washing bottles and the quartz tube were accurately rinsed with $100 \mathrm{~mL}$ of $1 \mathrm{M}$ $\mathrm{HNO}_{3}$ that was added to the $250 \mathrm{~mL}$ volumetric flask whose content was analyzed by atomic absorption spectrometry for the determination of Fe, Mn and $\mathrm{Zn}$.

All tests were carried out under the lab hood and the whole system was put under vacuum during the introduction of the boat in the furnace and before the flow of the gas, to avoid damage for the operator. The thermal tests were performed at 850, 1000 and $1200^{\circ} \mathrm{C}$, for samples with and without addition of charcoal and between 850 and $1200^{\circ} \mathrm{C}$, with steps of $50^{\circ} \mathrm{C}$ for samples with addition of fluff. The residence time was $30 \mathrm{~min}$ in all tests.

The recovery of the evaporated $\mathrm{Zn}$ and the $\mathrm{Mn}$ and $\mathrm{Fe}$ left in the residue were calculated by the difference between the amount of the metals present in the feed and that left in the residue after the thermal treatment. The purity of the evaporated zinc was calculated directly from the analysis of the liquid recovered at the end of the test, while the purity of $\mathrm{Mn}$ and $\mathrm{Fe}$ was that resulting from the analysis of the residue.

The recovery was also confirmed by the calculation of the reconstituted feed (metal in the residue plus metal obtained in the nitric aqueous) but the results had a higher variability so we preferred to use the first method.

\section{RESULTS}

The product and elemental analyses of car fluff, including a few heavy metals, are reported in Table 2 .

The XRPD patterns of the paste of spent batteries (the "feed" to the process) and of the residues after thermal treatment at $1200^{\circ} \mathrm{C}$ and $30 \mathrm{~min}$ in $\mathrm{CO}_{2}$ atmosphere are shown in Fig. 1. In the figure, the diffractograms of the residues obtained by treatment with activated charcoal $\left(\mathrm{CO}_{2}+\mathrm{C}\right)$ or and fluff $\left(\mathrm{CO}_{2}+\right.$ Fluff $)$ are compared with that resulting from treatment with $\mathrm{CO}_{2}$ alone.

The effects of temperature on the zinc recovery for samples submitted to different treatments $\left(\mathrm{CO}_{2}+\mathrm{C}, \mathrm{CO}_{2}\right.$ + Fluff and $\mathrm{CO}_{2}$ alone) are displayed in Fig. 2. Finally, the zinc purities of the materials resulting from such treatments are shown in Fig. 3.

\section{DISCUSSION}

The diffractogram of the feed sample reveals peaks attributable to graphite (carbon, indicated as $\mathrm{G}$ ), zincite $(\mathrm{ZnO}$, indicated as $\mathrm{Zn})$, hetaerolite $\left(\mathrm{ZnMn}_{2} \mathrm{O}_{4}\right.$, indicated as $\mathrm{He})$ and hausmannite $\left(\mathrm{Mn}_{3} \mathrm{O}_{4}\right.$, indicated as $\left.\mathrm{Ha}\right)$.

Besides, in the zinc-bearing compounds, zinc could be present in the spent batteries both as metallic zinc and as zinc oxide. The latter appears more probable from the results of X-ray analysis. Moreover, among five scientific papers perused, two of them (Freitas and De Pietre, 2004; Shin et al., 2009) report zinc in addition to zinc oxide, but the other three (De Souza et al., 2001, De Souza and Tenorio 2004; Ferella et al., 2008) report zinc oxide only. In addition, the wet process of shaking table applied on the paste of batteries should have oxidized most of zinc to zinc oxide. As soon as $\mathrm{CO}_{2}$ enters the heated zone of the furnace, the higher the temperature the more the Boudouard equilibrium Equation 1:

$$
\mathrm{CO}_{2}+\mathrm{C} \leftrightarrow 2 \mathrm{CO}
$$


Girolamo Belardi et al. / American Journal of Applied Sciences 11 (9): 1566-1573, 2014

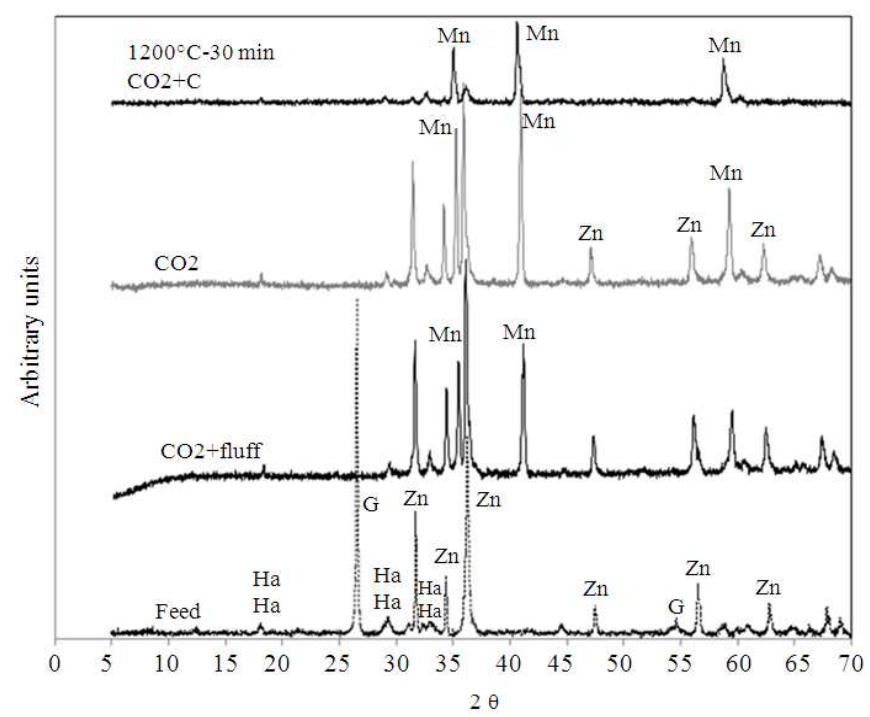

Fig. 1. XRPD spectra of the feed and of the residues of thermal treatment. G: Graphite; Ha: Hausmannite; He: Hetaerolite; Mn: Manganosite; Zn: Zincite

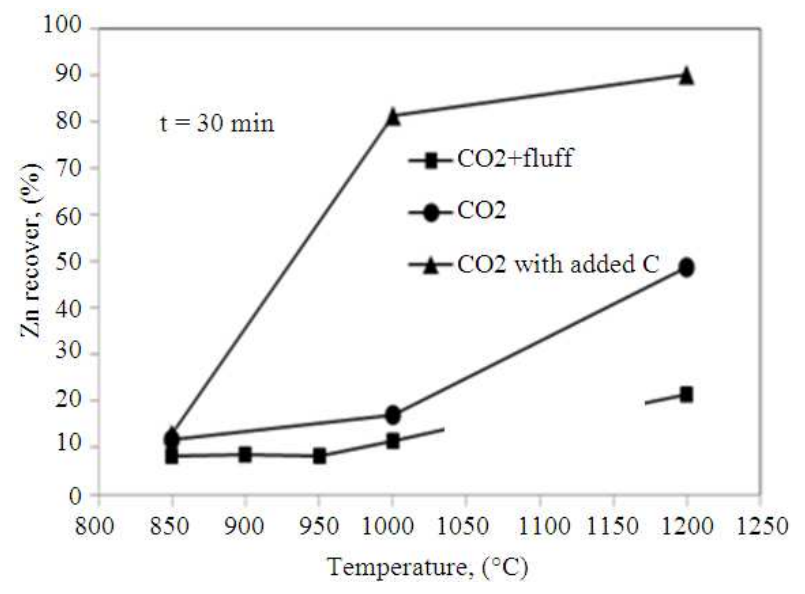

Fig. 2. Zinc recovery at different temperatures for a given treatment time (t)

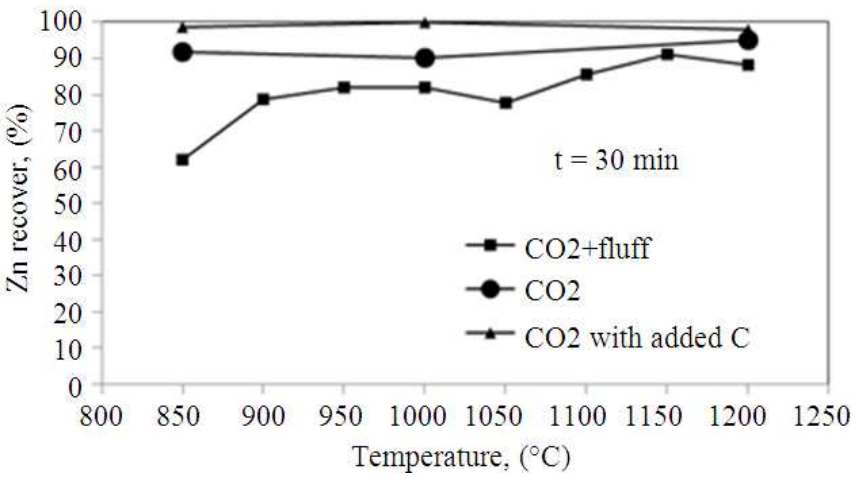

Fig. 3. Grade of zinc in the evaporated fraction for a given treatment time (t) 
Table 2. Product and elemental analysis of car fluff

\begin{tabular}{lcll}
\hline Component & Value (wt\%) & Element & Value (wt\%) \\
\hline Plastics & 63 & $\mathrm{C}$ & 45 \\
- PP & 25 & $\mathrm{H}$ & 5 \\
- PE & 5 & $\mathrm{Cl}$ & 4 \\
- PVC & 10 & $\mathrm{~N}$ & 1 \\
- ABS & 8 & $\mathrm{~S}$ & 1 \\
- PU & 8 & & \\
- PA & 6 & Heavy metals & \\
- n.d. & 38 & $\mathrm{Cd}$ & $69 \mathrm{ppm}$ \\
Rubbers & 9 & $\mathrm{Cr}$ & $826 \mathrm{ppm}$ \\
Cables/wires & 2 & $\mathrm{Cu}$ & $4800 \mathrm{ppm}$ \\
Metals & 2 & $\mathrm{~Pb}$ & $2740 \mathrm{ppm}$ \\
Glass/other & 24 & $\mathrm{Zn}$ & $6900 \mathrm{ppm}$ \\
\hline
\end{tabular}

is shifted to the right toward a higher partial pressure of CO. In this condition, zinc oxide can be reduced to metallic zinc according to the following reaction Equation 2:

$$
\mathrm{ZnO}+\mathrm{CO} \rightarrow \mathrm{Zn} \uparrow+\mathrm{CO}_{2}
$$

And the whole process can be expressed with the following reaction Equation 3:

$$
\mathrm{ZnO}+\mathrm{C} \rightarrow \mathrm{Zn} \uparrow+\mathrm{CO}
$$

Moreover, the decomposition of hetaerolite occurs according to the following reaction Equation 4:

$$
\mathrm{ZnMn}_{2} \mathrm{O}_{4}+2 \mathrm{CO} \rightarrow \mathrm{Zn} \uparrow+2 \mathrm{MnO}+2 \mathrm{CO}_{2}
$$

Proof of this reaction is the disappearance of hetaerolite and the appearance of manganosite, as shown by the X-ray patterns of Fig. 1. When this happens, the recovery of zinc is high, while it is low when manganosite does not form from hetaerolite and this phase is still present in the residue. When fluff is used, reactions (1) and (2) do not proceed to completion, probably due to the low level of available carbon and the recovery of zinc is quite low $\left(21 \%\right.$ at $\left.1200^{\circ} \mathrm{C}\right)$, as can be seen from Fig. 2. In the presence of carbon dioxide alone, the recovery of zinc is higher $\left(48 \%\right.$ at $\left.1200^{\circ} \mathrm{C}\right)$ than that obtained with the addition of fluff. In other words, there seems to be a negative interaction between the carbon naturally present in the paste of batteries and the fluff added from the outside, at least with the stoichiometric excess used (30\%). In contrast, in the presence of carbon dioxide and carbon, the reaction: $\mathrm{CO}_{2}+\mathrm{C} \rightarrow 2 \mathrm{CO}$ is complete, so that reaction (2) can take place and the recovery of zinc is considerably higher $\left(90 \%\right.$ at $\left.1200^{\circ} \mathrm{C}\right)$.

The analysis carried out on the residue after heating of the paste with addition of fluff shows that the peak of graphite disappears while those of zincite and of the other $\mathrm{Zn}$ - and Mn-bearing phases are still present. Moreover, the peaks of Manganosite (MnO, indicated as $\mathrm{Mn}$ ) begin to appear.

When no fluff is added to the sample, the X-ray pattern in the presence of only carbon dioxide, is very similar to the previous one (addition of fluff), being Zincite $(\mathrm{ZnO})$ and Manganosite $(\mathrm{MnO})$ the main phases present in the residue.

Regarding the sample with addition of elemental carbon, the XRPD analyses carried out on the residue after heating at $1200^{\circ} \mathrm{C}$ confirm that the reduction/volatilization process resulting from reaction (2) is complete. In fact, XRPD results show a strong decrease of all the peaks of Zincite $(\mathrm{ZnO})$ and the other $\mathrm{Zn}$-and Mn-bearing phases (hetaerolite and hausmannite) and is confirmed by the only presence of Manganosite $(\mathrm{MnO})$ in the residue. This behaviour is well correlated with the recovery of $\mathrm{Zn}$ in the evaporated fraction, as shown in Fig. 2. A zinc purity of about $95 \%$ is obtained utilizing carbon dioxide with or without addition of external carbon, while a purity of around $85 \%$ is obtained using carbon dioxide and fluff.

The purity of zinc in the evaporated fraction was evaluated by considering only the three main metals ( $\mathrm{Zn}$, $\mathrm{Mn}$ and $\mathrm{Fe}$ ). Chemical analysis of minor elements was carried out on the evaporated fraction attained by the test carried out at $1200^{\circ} \mathrm{C}$ and $30 \mathrm{~min}$, which gave the highest purity of zinc. Some minor elements, such as lead and cadmium, were detected, but in percentages below $0.3 \%$. Moreover, the purity of manganese in the residue increased with temperature.

\section{PROPOSED RECOVERY PROCESS}

Based on the results of the experimental tests for the recovery of zinc and manganese from the paste of spent batteries, an industrial-scale process was proposed in the flow sheet shown in Fig. 4. 


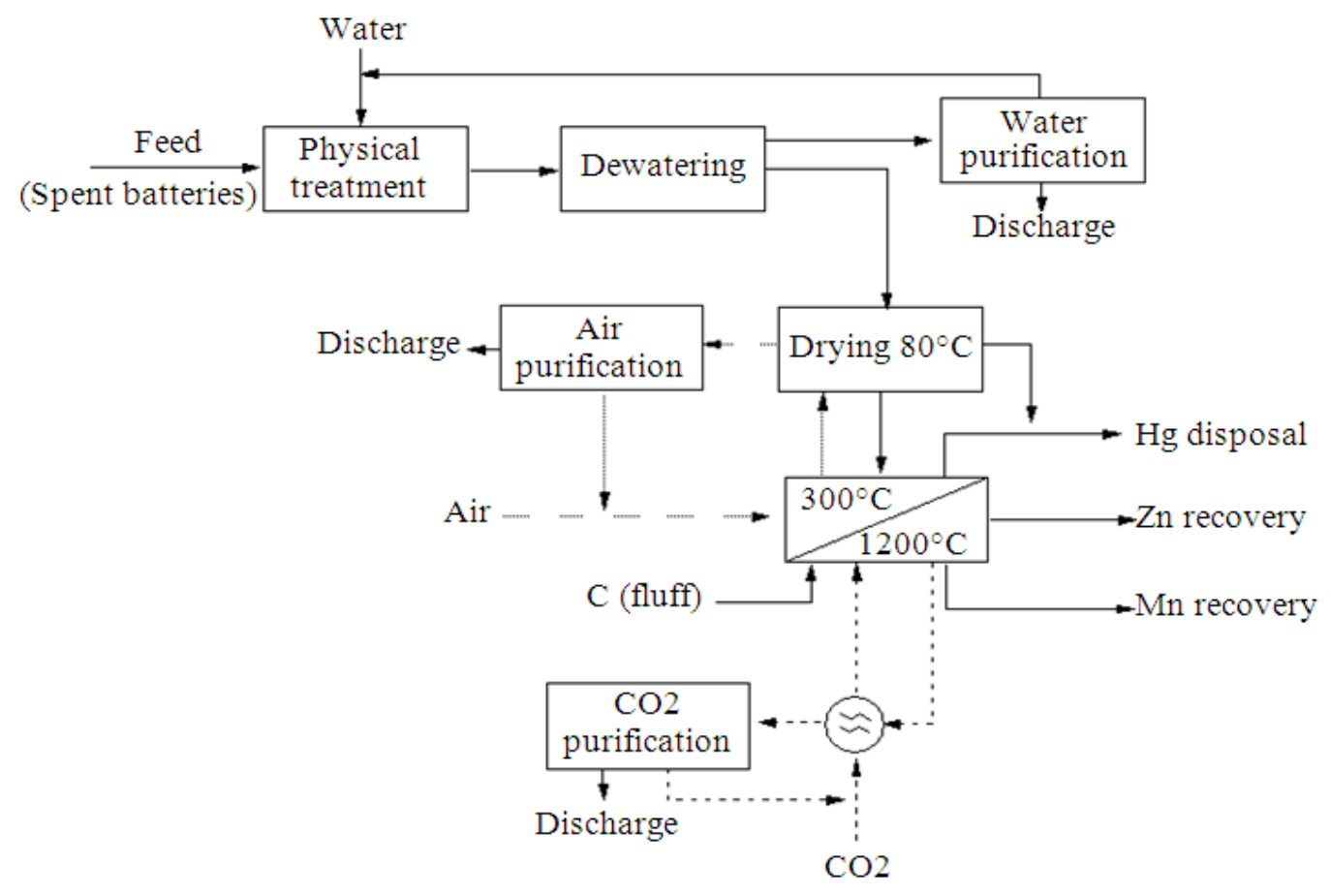

Fig. 4. Proposed flow sheet for metals recovery

This also includes a thermal desorption step for the removal of mercury if the paste of batteries contains a high concentration of this metal (Belardi et al., 2012).

After a physical separation to remove iron, plastic, paper and anodic collectors and a dewatering step to remove most of chlorides that could wear out the structures of the desorption plant and a dewatering step, the material is dried at $80^{\circ} \mathrm{C}$ and then sent to a furnace in air $\left(300-400^{\circ} \mathrm{C}\right)$ for mercury removal. In fact, thermal desorption of mercury occurs at relatively low temperature, both if the metal is present as elemental $\mathrm{Hg}$ and if it is present as metal Oxide ( $\mathrm{HgO})$. The $\mathrm{Mn}$ - and $\mathrm{Zn}$-enriched material is fed to a separate furnace in which the temperature is increased up to $1200^{\circ} \mathrm{C}$ and the air replaced by a stream of carbon dioxide. In this reactor, operating at $1200^{\circ} \mathrm{C}$, carbon or fluff is added to the paste of batteries, so that the reactions of reduction and volatilization of zinc can take place.

The core of the process is represented by the proposed pyrometallurgical treatment that works in two different stages: At $350^{\circ} \mathrm{C}$ metallic mercury is removed in an air stream, while at $1200^{\circ} \mathrm{C}$ high-purity volatilized metallic zinc is recovered in a stream of $\mathrm{CO}_{2}$ while the residue consists of manganese oxides, mainly Manganosite (MnO). The plant could also be provided with a purification system for process air, carbon dioxide and water to permit only the necessary make-up.

Thermal desorption appears to be a particularly promising process because it provides high metal recoveries and a good purity of zinc and manganese. After refining, these metals could be recycled for the production, respectively, of new batteries or of ironmanganese alloys.

\section{CONCLUSION}

The results of this study demonstrate that manganese and zinc can be recovered from zinccarbon and alkaline spent batteries. In particular, according to the proposed thermal process, a recovery of $90 \%$ zinc can be obtained at the temperature of $1200^{\circ} \mathrm{C}$ by using carbon dioxide and carbon addition to the paste of spent batteries. In the presence of carbon dioxide alone, the recovery of zinc is of $48 \%$, while a recovery of $21 \%$ is obtained with carbon dioxide and fluff addition. Manganese remains in the 
residue and recoveries around $100 \%$ can be obtained under the temperature conditions employed. The main phases found in this residue are Manganosite $(\mathrm{MnO})$ and Zincite $(\mathrm{ZnO})$.

The proposed process allows the recovery of zinc and manganese from a waste consisting of spent zinccarbon and alkaline batteries. In addition, another waste, carbon dioxide, an industrial by-product, can be used in the process. Although at present the use of fluff seems to be not beneficial with the low stoichiometric excess utilized, the effect of higher amounts of fluff on zinc conversion and recovery should be further explored in future research. In any case, the results of our study clearly indicate that the implementation of the proposed process on the industrial scale could not only provide economic benefits but also contribute to resource conservation and waste minimization.

\section{ACKNOWLEDGEMENT}

The authors wish to thank Dr. Mauro Ferrini and Mrs. Stefania Pontecorvo for technical support in chemical analyses and Dr. Eng. Livia Mammarella for reading of the paper.

\section{REFERENCES}

Almeida, M.F., S.M. Xará, J. Delgado and C.A. Costa, 2009. Laboratory study on the behaviour of spent AA household alkaline batteries in incineration. Waste Manage., 29: 342-349. DOI: 10.1016/j.wasman.2008.03.011

Alunno Rossetti, V., L.D. Palma and F. Medici, 2006. Production of aggregate from non-metallic automotive shredder residues. J. Hazard. Mat., 137: 1089-1095. DOI: 10.1016/j.jhazmat.2006.03.048

Belardi, G., P. Ballirano, M. Ferrini, R. Lavecchia and F. Medici et al., 2011. Characterization of spent zinc-carbon and alkaline batteries by SEM/EDS, TGA/DTA and XRD analysis. Thermochim. Acta, 526: 169-177. DOI: 10.1016/j.tca.2011.09.012

Belardi, G., R. Lavecchia, F. Medici and L. Piga, 2012. Thermal treatment for recovery of manganese and zinc from zinc-carbon and alkaline spent batteries. Waste Manage., 32: 158166. DOI: 10.1016/j.wasman.2012.05.008
Belardi, G., F. Medici and L. Piga, 2014. Influence of gaseous atmosphere during a thermal process for recovery of manganese and zinc from spent batteries. J. Power Sources, 248: 1290-1298. DOI: 10.1016/j.jpowsour.2013.10.064

Bernardes, A.M., D.C.R. Espinosa and J.A.S. Tenorio, 2004. Recycling of batteries: a review of current processes and technologies. J. Power Sources, 130: 291-298. DOI: 10.1016/j.jpowsour.2003.12.026

De Michelis, I., F. Ferella, E. Karakaya, F. Beolchini and F. Vegliò, 2007. Recovery of zinc and manganese from alkaline and zinc-carbon spent batteries. J. Power Sources, 172: 975-983. DOI: 10.1016/j.jpowsour.2007.04.092

De Souza, C.C.B.M. and J.A.S. Tenorio, 2004. Simultaneous recovery of zinc and manganese dioxide from household alkaline batteries through hydrometallurgical processing. J. Power Sources, 136: 191-196. DOI: 10.1016/j.jpowsour.2004.05.019

De Souza, C.C.B.M., D.C. De Oliveira and J.A.S. Tenorio, 2001. Characterization of used alkaline batteries powder and analysis of zinc recovery by acid leaching. J. Power Sources, 103: 120-126. DOI: $10.1016 / \mathrm{S} 0378-7753(01) 00850-3$

Ferella, F., I. De Michelis and F. Vegliò, 2008. Process for the recycling of alkaline and zinccarbon spent batteries. J. Power Sources, 183: 805-811. DOI: 10.1016/j.jpowsour.2008.05.043

Freitas, M.B.J.G. and M.K. De Pietre, 2004. Electrochemical recycling of the zinc from spent $\mathrm{Zn}-\mathrm{MnO}_{2}$ batteries. J. Power Sources, 128: 343349. DOI: 10.1016/j.jpowsour.2003.09.054

Karnchanawong, S. and P. Limpiteeprakan, 2009. Evaluation of heavy metal leaching from spent household batteries disposed in municipal solid waste. Waste Manage, 29: 550-558. DOI: 10.1016/j.wasman.2008.03.018

Marruzzo, G., F. Medici, L. Panei, L. Piga and G. Rinaldi, 2001. Characteristics and properties of a mixture containing fly ash, hydrated lime and an organic additive. Environ. Eng. Sci., 18: 159-165. DOI: $10.1089 / 109287501750281059$

Ruffino, B., S.Fiore and M.C. Zanetti, 2014. Strategies for the enhancement of Automobile Shredder Residues (ASRs) recycling: Results and cost assessment. Waste Manag., 34: 148-155. DOI: $10.1016 /$ j.wasman.2013.09.025 
Sayilgan, E., T. Kukrer, G. Civelekoglu, F. Ferella and A. Akcil et al., 2009. A review of technologies for the recovery of metals from spent alkaline and zinc-carbon batteries. Hydrometallurgy, 97: 158-166. DOI: 10.1016/j.hydromet.2009.02.008

Shin, S.M., G. Senanayake, J. Sohn, J. Kang and D. Yangand, 2009. Separation of zinc from spent zinc-carbon batteries by selective leaching with sodium hydroxide. Hydrometallurgy, 96: 349-353. DOI: 10.1016/j.hydromet.2008.12.010
USGS, 2014. Mineral commodity summaries.

Vermeulen, I., J. Van Caneghem, C. Block, J. Baevens and C. Vanf:decasteele, 2011. Automotive shredder residue (ASR): Reviewing its production from End-of-Life Vehicles (ELVs) and its recycling, energy or chemicals valorization. J. Hazard. Mat., 190: 8-27. DOI: 10.1016/j.jhazmat.2011.02.088 